\title{
A Novel Approach of Using Free Buccal Pad of Fat Combined With Modified Coronally Advanced Flap in Treating Localized Gingival Recession: A Technical Note
}

\section{Shehad Wael Saad, ${ }^{A}$ Doaa Adel-Khattab, ${ }^{\text {B }}$ Eman Khalil, ${ }^{A}$ Ahmed Y. Gamal ${ }^{\mathrm{B}, \mathrm{C}}$}

ADepartment of Oral Medicine, Periodontology, and Oral Diagnosis, Faculty of Dentistry, The British University in Egypt, Cairo, Egypt.

${ }^{B}$ Department of Oral Medicine, Periodontology, and Oral Diagnosis, Faculty of Dental Medicine, Ain Shams University, Cairo, Egypt.

CDepartment of Oral Medicine, Periodontology, and Oral Accepted for publication: Diagnosis, Faculty of Dental Medicine, $6^{\text {th }}$ of October University, Giza, Egypt.

\begin{abstract}
$\underline{\text { Abstract }}$
Background: Various surgical techniques have been proposed for the treatment of gingival recession (GR) in the form of either pedicled or free grafts. The free buccal pad of fat is an easy technique for harvesting a free graft for regenerative purposes and is currently gaining popularity and attention in the field of periodontology. The buccal fat pad is a fat tissue that is used as a novel source of mesenchymal cells (MSC). The aim of the current case report was to assess the efficacy of using a free buccal pad of fat in combination with a modified coronally advanced flap procedure (CAF) in treating localized gingival recession. Methods: A healthy 33year-old male presented with gingival recession type 1 (RT1) affecting his upper right canine and was suffering from continuous sensitivity. Phase I therapy was performed six weeks before surgery. A modified CAF was raised to expose the recipient site and a free buccal fat pad graft (FBFP) was harvested and sutured in place. Results: The color of the tissues was nearly homogeneous two weeks following the surgical procedure. Maximum root coverage was $66.6 \%$ achieved at one month. However, a gradual relapse of $25 \%$ was noticed through the follow-up at three and six months postoperatively. Conclusion: The use of the FBFP in combination with a modified CAF can be excluded as a successful regenerative method for treating GR. However, further studies and randomized controlled clinical trials are recommended to confirm the effectiveness of this technique for the treatment of GR in the long term.
\end{abstract}

Keywords: Gingival recession; modified coronally advanced flap; free buccal fat pad graft; periodontal regeneration

\section{Introduction}

Gingival recession (GR) is a term used to describe the apical migration of the gingiva beyond the cementoenamel junction (CEJ). ${ }^{1}$ Various surgical techniques have been proposed for the treatment of GR in the form of pedicled flaps or free grafting techniques. ${ }^{2,3}$ The coronally advanced flap procedure (CAF) can be described as a coronal repositioning of the gingiva apical to the CEJ to cover the exposed root. 4 This technique is considered the best method of treatment for GR when esthetics is the main concern. De Sanctis and Zucchelli recently proposed a modification of the CAF for the management of single recession cases claiming that this approach provides a better blood supply bed to the flap compared to the conventional technique. 5

In 1977, Egyedi was the first to introduce the use of the pedicled buccal fat pad flap for the closure of oroantral 
communications. ${ }^{6}$ Neder used the buccal fat pad as a free graft for oral reconstructive procedures. ${ }^{7}$ Agarwal et al. introduced to the literature the use of the pedicled buccal pad of fat in the treatment of severe gingival recession. In our case report, we aimed to use the free buccal fat pad graft (FBFP) rather than the pedicled graft, which would eliminate the limitation of its use only in the posterior teeth as was described by Agarwal et al. ${ }^{2}$

\section{Case Description and Results}

A healthy 33-year-old male presented with sensitivity in the upper right canine with gingival recession type 1 (RT1). Clinical examination showed a plaque index (PI) of $45 \%$ and a gingival index (GI) of $18 \% .^{8}$ The defect was probably caused by the selfinjurious habit of pushing a hard object on the gums based upon the patient's history (Figure 1). Phase I therapy was performed six weeks before surgery and the patient was instructed to maintain oral hygiene by brushing with a soft bristle toothbrush twice daily and flossing interproximally. After explaining the procedure to the patient, he was asked to sign a consent form. The technique was approved by the ethical committee of the Ain Shams University Faculty of Dental Medicine (approval number: RecIMo41804).

A coronally advanced flap was raised at the recipient site after injection of local anesthesia. ${ }^{5} 5$ Two horizontal incisions $3 \mathrm{~mm}$ in length were made at the base of the anatomical papillae using a split-thickness approach to create the surgical papillae for flap advancement. These incisions were located at a distance from the tip of the anatomical papillae equal to the depth of recession plus $1 \mathrm{~mm}$. Two slightly divergent incisions were released extending from the end of the previous horizontal incisions. A full-thickness flap was elevated starting from the margin of the gingiva reaching 3-4 $\mathrm{mm}$ past the exposed bone then continuing as a split-thickness extending to the alveolar mucosa beyond the mucogingival junction

a ARTINIBSA 4\% 1:200,ooo, Inibsa Dental, Spain b Curved Kelly scissors, Hu-Friedy, Chicago, Illinois, USA

c Gracey curettes, Hu-Friedy, Chicago, Illinois, USA

d Adcocycline 3\%, ADCO, El Talbia, Giza, Egypt
(MGJ). The anatomical papillae were deepithelialized using curved dissecting scissors (Figure 2). 5

A small horizontal incision was made opposite to the upper second molar using a no. 15 blade extending $1.5 \mathrm{~mm}$ into the vestibular depth. The buccal fat pad was gently held and dissected from the buccal mucosa using a rotational movement to allow its removal with dissecting scissors. ${ }^{b}$ The incision was sutured using the simple interrupted technique (Figure 3).

\section{Figure 1.}

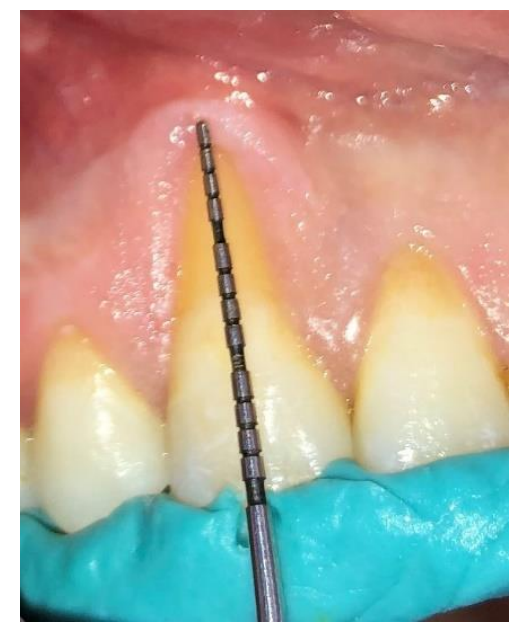

Preoperative intraoral photograph showing recession depth measurement using a stent for standardization

After flap elevation, the root surface was debrided using a 5/6 Gracey curettec followed by root conditioning with a tetracycline solutiond (250 mg tetracycline/ 5 $\mathrm{ml}$ saline). The previously prepared FBFP was placed over the exposed root and fixed with (polyglactin 910) 4-0 interrupted sutures.e The flap was positioned just coronal to the CEJ with polyglycolic acid (PGA) 5-0 sling sutures (Figure 4).

Postoperatively, the patient was prescribed amoxicillin clavulanate ${ }^{\mathrm{f}} 1 \mathrm{gm}$ tablets every 12 hours and metronidazoleg $500 \mathrm{mg}$ every eight hours. Ibuprofen ${ }^{\mathrm{h}}$ 400mg was prescribed as needed. The patient was instructed to use $0.12 \%$ chlorhexidine ${ }^{i}$ mouthwash three times daily and to eat a soft diet. The sutures were removed 14 days after surgery and the patient was instructed to gently brush his

e Vicryl, Ethicon, Johnson \& Johnson, Raritan, New Jersey, USA

f Augmentin, GlaxoSmithKline, United Kingdom

g Flagyl, Sanofi, Paris, France

h Brufen, Abbott, Abbott Park, Illinois, USA

i Hexitol, ADCO, Egypt 
teeth with a soft brush. Clinical assessment was performed at baseline, one, three, and six months postoperatively by recording probing depth (PD), clinical attachment level (CAL), recession depth (RD), recession

\section{Figure 2.}
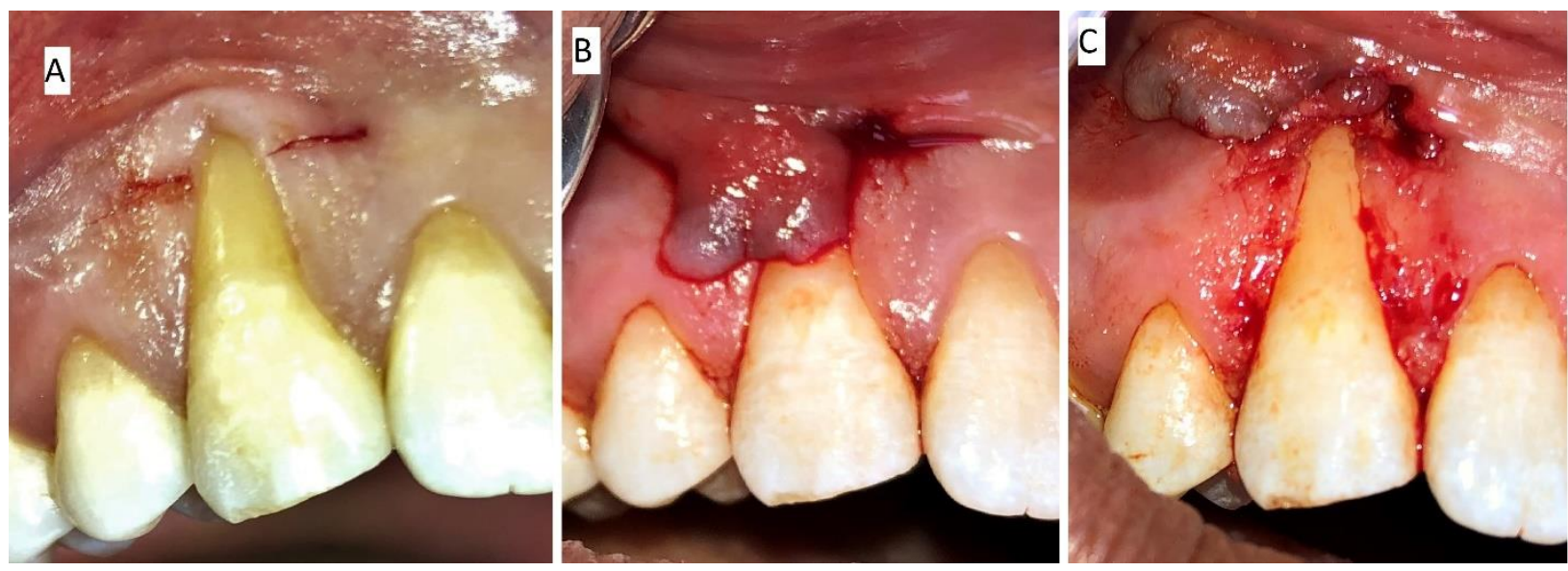

Clinical photographs showing modified coronally advanced flap; A. Two horizontal beveled incisions are made mesial and distal to upper right canine; B. Flap was elevated using a split-full-split approach in the coronal-apical direction; C. Split thickness flap after de-epithelialization of the papillae

Figure 3.
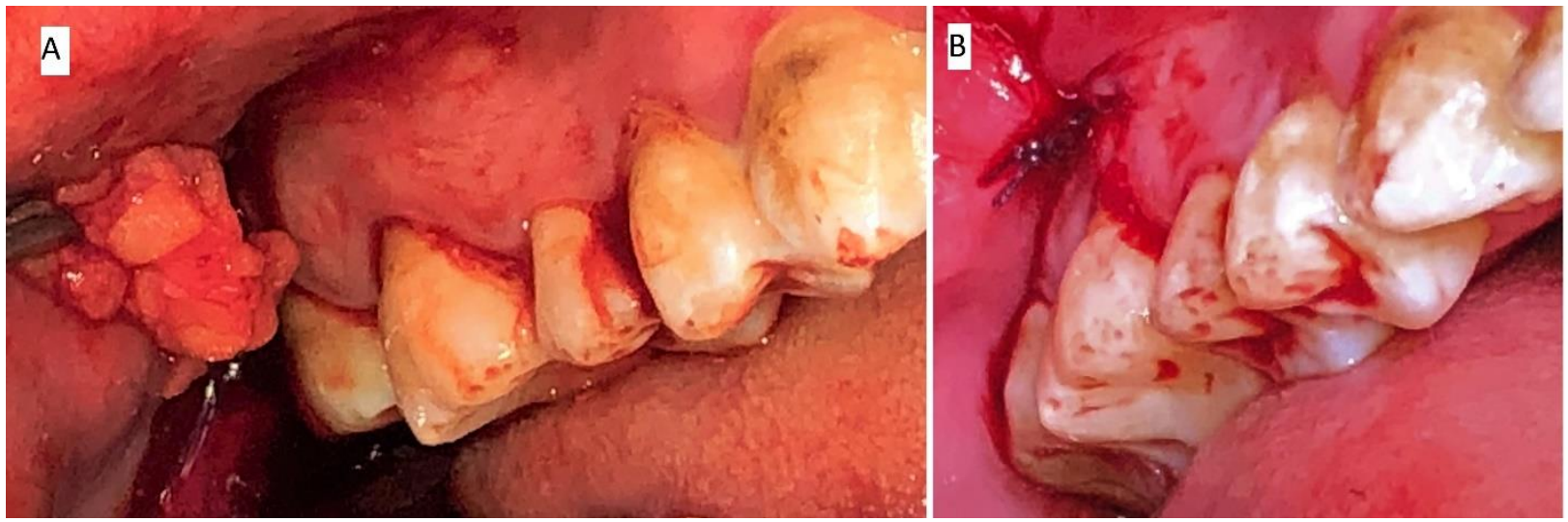

Intraoral photographs showing FBFP harvesting technique; A. Simple incision was made opposite to upper second molar and a curved hemostat was used for blunt dissection of FBFP; B. Simple interrupted suture of donor site

Figure 4.
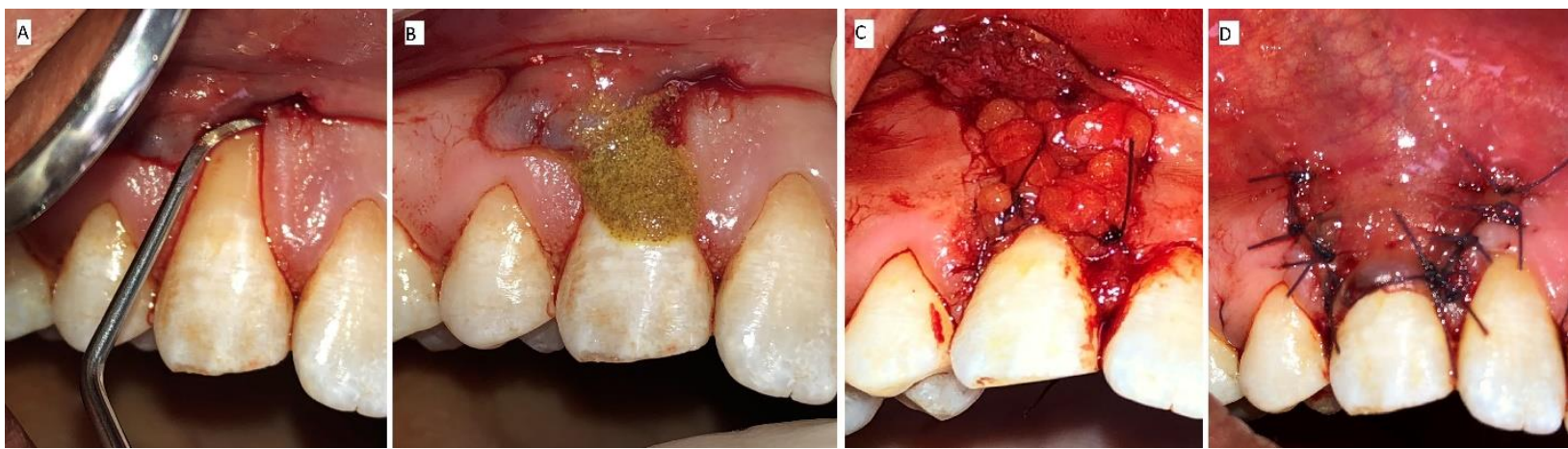

Intraoral photographs showing recipient site; A. Root surface debridement using 5/6 Gracey curette; B. Root surface conditioning with tetracycline; C. FBFP sutured in place; D. Flap closure using sling suture

The healing process was uneventful, and the patient reported slight swelling and discomfort the first three days of the overall postoperative period with no signs of necrosis or hemorrhage at the donor site. The patient gave a 3 out of 10 on the visual analogue scale (VAS) and he did not need any analgesics postoperatively. $9 \mathrm{He}$ also reported that postoperative hypersensitivity resolved completely.

The color of the tissues was nearly homogeneous two weeks following the surgical procedure. The clinical measurements taken at baseline, one 
month, three months, and six months postoperatively are shown in Table 1. Maximum root coverage was $66.6 \%$ achieved at one month. However, a gradual relapse of $25 \%$ was noticed through the follow-up periods at three and six months postoperatively. No gain in WKT was achieved but an increase in GT from $1 \mathrm{~mm}$ to $2 \mathrm{~mm}$ was noted (Figures 5 and 6 ).

\section{Figure 5.}
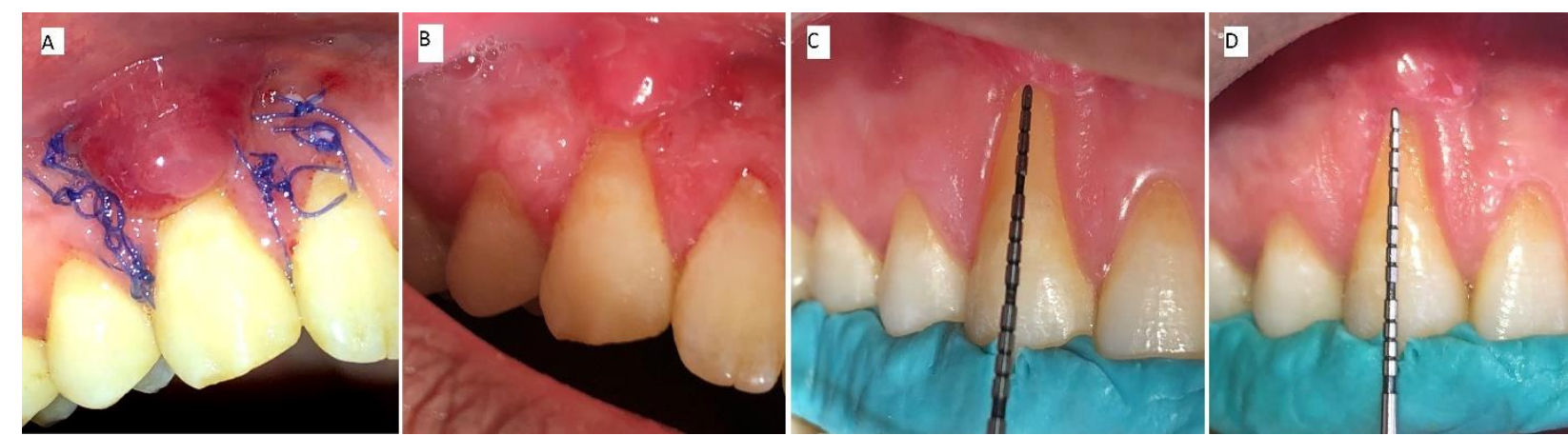

A. Fourteen days postoperative before suture removal; B. One month follow up; C. Recession depth measurement at three months postoperative; D. Recession depth measurement at six months postoperative

\section{Figure 6.}
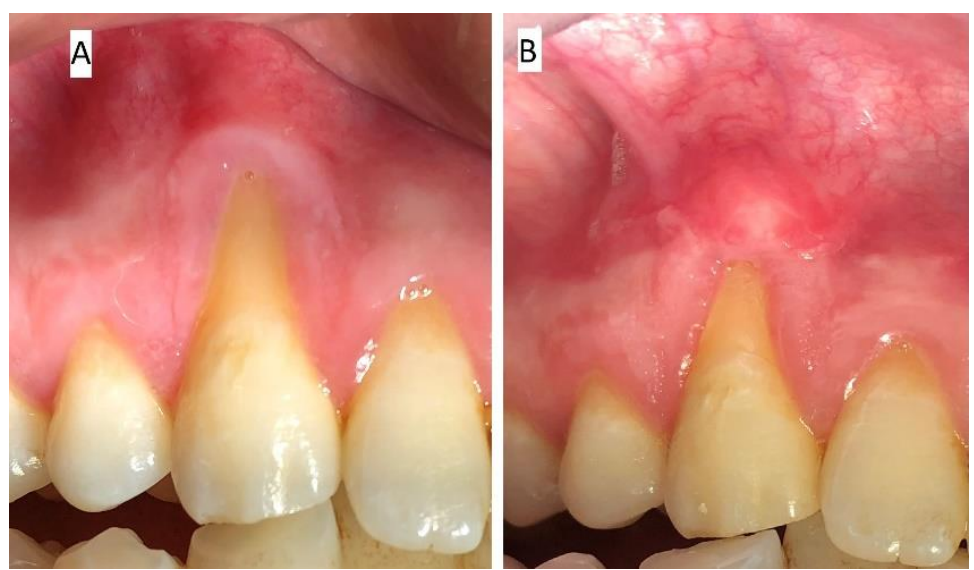

A. Preoperative intraoral photograph at baseline; B. Six months postoperative

Table 1. Summary of follow-up data

\begin{tabular}{|c|c|c|c|c|}
\hline & Baseline & $\begin{array}{c}\text { One Month } \\
\text { Postoperative }\end{array}$ & $\begin{array}{c}\text { Three Months } \\
\text { Postoperative }\end{array}$ & $\begin{array}{c}\text { Six Months } \\
\text { Postoperative }\end{array}$ \\
\hline RD (mm) & 6 & 2 & 4.5 & 4.5 \\
\hline RW $(\mathbf{m m})$ & 5 & 4 & 4 & 4 \\
\hline MRC\% & N/A & 66.6 & 25 & 25 \\
\hline WKT (mm) & 2 & & 2 & 2 \\
\hline GT $(\mathbf{m m})$ & 1 & & 2 & 2 \\
\hline
\end{tabular}

RD: recession depth; RW: recession width; MRC: maximum root coverage; WKT: width of keratinized tissue; GT: gingival thickness

\section{Discussion}

In the current case report the modified technique described by Zucchelli et al. was used for the CAF. ${ }^{10}$ The buccal fat pad was also harvested as a free graft in order to overcome the limitations of the pedicled buccal pad of fat that was restricted to upper posterior teeth. ${ }^{11}$ Deliberador et al. used a free fat graft to manage isolated Miller class II recession and found in a split mouth study that the use of FBFP in combination with CAF gave similar results to the classical approach using connective tissue grafts. ${ }^{12}$

Regarding this case, the soft tissue thickness increased from a thin gingival phenotype of $1 \mathrm{~mm}$ to a thicker one of $2 \mathrm{~mm}$ without any change in WKT. This was in accordance with Kablan et al. who had a similar increase in soft tissue thickness following FBFP in a case series. ${ }^{13}$ However, in the present study, a gradual relapse of the percentage of mean root coverage was observed from a $66 \%$ gain one month 
postoperatively to $25 \%$ six months postoperatively. This result may be attributed to the consistency of the buccal fat pad, which is friable and slippery, and to the compromised vascularization of the buccal fat pad in the free harvesting approach compared to the pedicled approach.

In this case report the patient presented with a deep recession that was indicated for a combined technique. The performance of CAF alone does not give long-term root coverage stability according to Pini-Prato et al. in their five-year split mouth study. ${ }^{14}$ Moreover, it was shown in a randomized controlled trial comparing between CAF alone versus CAF combined with a connective tissue graft in the treatment of single Miller class I or II recession, that the latter provided a better long-term outcome in all clinical parameters throughout the follow-ups. ${ }^{15}$

Conclusively, the use of the buccal fat pad as a free graft is not a successful technique to be combined with $\mathrm{CAF}$ and seems to compromise root coverage outcomes. However, normal soft tissue color and texture in relation to the surrounding tissue and a slight gain in gingival thickness may be observed. Further studies and randomized controlled clinical trials are recommended to compare the use of the buccal fat pad as a free graft versus the pedicled ones for treatment of GR.

\section{$\underline{\text { References }}$}

1. Leonard RH Jr, Smith LR, Garland GE, Caplan DJ. Desensitizing agent efficacy during whitening in an atrisk population. $J$ Esthet Restor Dent. 2004; 16(1):49-55; discussion 56. https://doi.org/10.1111/j.17088240.2004.tboo452.x

2. Agarwal C, Gayathri GV, Mehta DS. An innovative technique for root coverage using pedicled buccal fat pad. Contemp Clin Dent. 2014; 5(3):386-388.

https://doi.org/10.4103/0976237X.137963

3. Cairo F, Pagliaro U, Nieri M. Treatment of gingival recession with coronally advanced flap procedures: a systematic review. $J$ Clin

Periodontol. 2008 Sep; 35(8

Suppl):136-62.

https://doi.org/10.1111/j.1600-

051X.2008.01267.X

4. Zucchelli G, Mele M, Mazzotti C, Marzadori M, Montebugnoli L, De Sanctis M. Coronally advanced flap with and without vertical releasing incisions for the treatment of multiple gingival recessions: a comparative controlled randomized clinical trial. J Periodontol. 2009 Jul; 8o(7):1083-1094. https://doi.org/10.1902/jop.2009.o 90041

5. de Sanctis M, Zucchelli G. Coronally advanced flap: a modified surgical approach for isolated recession-type defects: three-year results. J Clin Periodontol. 2007 Mar; 34(3):262268. https://doi.org/10.1111/j.1600051X.2006.01039.X

6. Egyedi P. Utilization of the buccal fat pad for closure of oro-antral and/or oro-nasal communications. $J$ Maxillofac Surg. 1977 Nov; 5(4):241244. https://doi.org/10.1016/s03010503(77)80117-3

7. Neder A. Use of buccal fat pad for grafts. Oral Surg Oral Med Oral Pathol. 1983 Apr; 55(4):349-350. https://doi.org/10.1016/o0304220(83)90187-1

8. Ainamo J, Bay I. Problems and proposals for recording gingivitis and plaque. Int Dent J. 1975 Dec; 25(4):229-235.

9. Price DD, Bush FM, Long S, Harkins SW. A comparison of pain measurement characteristics of mechanical visual analogue and simple numerical rating scales. Pain. 1994 Feb; 56(2):217-226. https://doi.org/10.1016/03043959(94)90097-3

10. Zucchelli G, De Sanctis M. Treatment of multiple recession-type defects in patients with esthetic demands. $J$ Periodontol. 2000 Sep; 71(9):1506- 
1514 .

https://doi.org/10.1902/jop.2000.71 .9 .1506

11. El Haddad SA, Abd El Razzak MY, El Shall M. Use of pedicled buccal fat pad in root coverage of severe gingival recession defect. $J$ Periodontol. 2008 Jul; 79(7):12711279.

https://doi.org/10.1902/jop.2008.07 0176

12. Deliberador TM, Trevisani CT, Storrer CL, et al. Non-Pedicled Buccal Fat Pad Grafts to Treatment for Class I and II Gingival Recessions: A Clinical Trial. Braz Dent J. 2015 Nov-Dec; 26(6):572579; https://doi.org/10.1590/o1036440201300432

13. Kablan F. The use of Buccal fat pad free graft in regenerative treatment of peri-implantitis: A new and predictable technique. Ann Maxillofac Surg. 2015; 5(2):179-184. https://doi.org/10.4103/22310746.175759

14. Pini-Prato GP, Cairo F, Nieri M, Franceschi D, Rotundo R, Cortellini P. Coronally advanced flap versus connective tissue graft in the treatment of multiple gingival recessions: a split-mouth study with a 5-year follow-up. J Clin

Periodontol. 2010 Jul; 37(7):644650. https://doi.org/10.1111/j.160o051X.2010.01559.X

15. Kuis D, Sciran I, Lajnert V, et al. Coronally advanced flap alone or with connective tissue graft in the treatment of single gingival recession defects: a long-term randomized clinical trial. J Periodontol. 2013 Nov; 84(11):1576-1585. https://doi.org/10.1902/jop.2013.12 o451

Conflicts of interest: The authors declared no conflicts of interest related to this work.

\section{Corresponding author:}

Dr. Ahmed Y. Gamal

Professor and Chair, Department of Oral

Medicine, Periodontology, and Oral

Diagnosis

Faculty of Dental Medicine

Ain Shams University

Cairo, Egypt

E-mail: hgamal1@hotmail.com

Phone: +20 1006607176

This is an open access article distributed under the Creative Commons AttributionNoncommercial-NoDerivatives 4.0 International (CC BY-NC-ND 4.0) License. 